\title{
BMJ Open How is television time linked to cardiometabolic health in adults? A critical systematic review of the evidence for an effect of watching television on eating, movement, affect and sleep
}

\author{
Janelle M Wagnild (D), Tessa M Pollard
}

To cite: Wagnild JM, Pollard TM. How is television time linked to cardiometabolic health in adults? A critical systematic review of the evidence for an effect of watching television on eating, movement, affect and sleep. BMJ Open 2021;11:e040739. doi:10.1136/ bmjopen-2020-040739

- Prepublication history and additional supplemental material for this paper are available online. To view these files, please visit the journal online (http://dx.doi.org/10.1136/ bmjopen-2020-040739).

Received 20 May 2020 Revised 13 April 2021 Accepted 17 April 2021
D) Check for updates

(C) Author(s) (or their employer(s)) 2021. Re-use permitted under CC BY-NC. No commercial re-use. See rights and permissions. Published by BMJ.

Department of Anthropology, Durham University, Durham, UK

\section{ABSTRACT}

Objective To improve our understanding of how television (TV) time is linked to cardiometabolic health among adults by systematically and critically evaluating the evidence that watching TV is associated with increased food consumption, lack of movement or negative affect or affects subsequent sleep.

Design Systematic review.

Data sources Web of Science and PubMed.

Eligibility criteria Studies that provided quantitative evidence on short-term associations of watching TV with dietary intake, characteristics of sitting, affect and sleep among samples of healthy adults ( $\geq 18$ years old). Data extraction and synthesis Study quality was assessed using the National Heart, Lung, and Blood Institute Quality Assessment Tools; studies deemed to be of low quality were excluded from the review. Due to heterogeneity of study designs and measurements, the findings were synthesised using narrative summary accompanied by custom plots.

Results We identified 31 studies that met the inclusion criteria. Most of the associations reported by the studies included in this review were weak or inconsistent. There was no strong evidence to suggest that food consumption is higher while watching TV than in other contexts or that TV is a particularly 'sedentary' behaviour. Affect was less likely to be positive while watching TV than in other contexts but was not more likely to be negative. Two small studies suggest that TV may impact sleep via suppressing melatonin and delaying bedtime.

Conclusion There is currently no strong evidence to suggest that TV might impact cardiometabolic health via increasing food consumption, being linked with prolonged/ inactive sitting, affect or subsequent sleep. Additional research is required to understand how TV fits within everyday lives and relates to eating, sitting, affect and sleep to improve our understanding of how it might impact cardiometabolic health.
Strengths and limitations of this study

- This review synthesises for the first time a diverse body of evidence that tests for associations between watching TV and food consumption, characteristics of sitting, mood/affect and sleep, to shed light on mechanisms by which TV time might impact cardiometabolic health.

- A systematic approach was taken in gathering and appraising the evidence.

- Custom plots were produced to visualise the findings of individual studies, including the magnitude, direction and statistical significance of associations.

- The outcomes and designs of included studies were too heterogeneous for estimating overall summary estimates using meta-analysis.

\section{INTRODUCTION}

Television (TV) time has been associated with poor cardiometabolic health outcomes among adults, including cardiovascular mortality, ${ }^{12}$ incidence of type 2 diabetes $^{12}$ and increases in adiposity. ${ }^{3}$ TV time is generally assumed to be sedentary and sedentary time is now a well-established risk factor for poor cardiometabolic health. ${ }^{1} 4$ However, the association between TV time and poor health outcomes is stronger than the association between total sitting time and poor health outcomes ${ }^{15}$ or than between time spent sitting in other contexts, such as sitting at work, and health outcomes. ${ }^{6-9}$ For studies based entirely on self-reported measures, lower measurement error in the assessment of TV time than in the assessment of other sedentary behaviours is likely to contribute to such a difference. ${ }^{10-12}$ However, the relationship between self-reported TV time and cardiometabolic outcomes is also stronger 
than the relationship between objectively assessed sedentary time and those same outcomes, ${ }^{13-15}$ a finding that is unlikely to be attributable to measurement error. It is possible that TV time has a particularly adverse impact on cardiometabolic health and this suggestion is repeatedly made in the literature. ${ }^{15716}$

Several possible explanations for the larger observed effects of TV time have been put forth. Most commonly, it has been suggested that dietary intake while watching TV (particularly snacking) may contribute to its effect. ${ }^{15} 716$ It has also been suggested that the way in which sitting occurs while watching TV may be important, for example, if it is characterised by particularly low energy expenditure (EE) or low levels of muscular activation. ${ }^{1516}$ Detrimental impacts of TV on sleep and mental health (potentially partly via short-term affective responses) have also been noted as potential mechanisms by which TV might adversely impact cardiometabolic health. ${ }^{16-18}$ However, the evidence lending support to these suggested possible explanations has not, to our knowledge, been exhaustively or critically evaluated.

The purpose of this critical systematic review is to improve our understanding of how TV time is linked to cardiometabolic health among adults. To this end, we have critically evaluated the available literature that provides evidence regarding short-term associations between watching TV and food consumption, characteristics of sitting, affect, and sleep.

\section{METHODS}

\section{Eligibility criteria}

Studies were eligible for inclusion in the review if they provided quantitative evidence of dietary intake, characteristics of sitting, or affect while watching TV or subsequently on the same day as watching TV, or on sleep subsequently on the same day. Studies could be experimental or observational as long as they described behaviours while watching TV or on the same day subsequent to watching TV. Participants in the studies had to be non-institutionalised adults ( $\geq 18$ years old) who were not exclusively characterised by a particular health status (eg, only overweight or obese adults). All studies had to be published in English in 2000 or later as TV viewing practices change over time.

\section{Information sources and search strategy}

The literature was searched in March 2021 using Web of Science Core Collections and PubMed. The search strategy included terms to identify studies that measured TV time across all disciplines (online supplemental file 1 ). The reference lists of all included papers were also checked. We had initially set out to address a broader research question, aiming to capture all studies that examined TV time in relation to any factors that might impact cardiometabolic health; the search strategy was therefore intentionally broad and we did not specify outcome variables of interest a priori. Given the diversity of studies identified, we subsequently chose to narrow the scope of our research question to focus only on studies that measured the variable of interest while watching TV (or immediately after) among adults.

\section{Study selection}

The titles and abstracts of the retrieved studies were screened for relevance. A subsample (10\%) was independently screened by both authors to ensure agreement and consistency; any discrepancies were discussed until an agreed application of inclusion and exclusion criteria was reached, then one author (JW) screened the remainder of titles and abstracts. The full-texts of studies with relevant abstracts were consulted to determine eligibility. Both authors confirmed the eligibility of each full-text, and any cases of disagreement were resolved through discussion.

\section{Quality assessment}

The quality of each eligible full-text was assessed based on the National Heart, Lung, and Blood Institute Quality Assessment Tools for observational cohort and cross-sectional studies (for observational studies) and for controlled intervention studies (for experimental and intervention studies) (https://www.nhlbi.nih.gov/ health-topics/study-quality-assessment-tools). In order to draw on the highest standards of evidence, studies deemed to have low internal validity based on the quality appraisal were excluded from the review. The quality assessment of each study was confirmed by both authors and any disagreements were discussed until consensus was reached.

\section{Data extraction}

The data from each eligible study were extracted into a spreadsheet with predefined columns for the general study details (location, date), study design, methodology, sample characteristics, statistical analyses (including covariates) and main findings regarding the behaviour(s) of interest .

\section{Synthesis of results}

The results of the associations between TV time and the outcome of interest were organised by categories of outcome variables that emerged from the search (diet, characteristics of sitting, affect, sleep). Because of heterogeneity of study outcomes and study designs, meta-analysis was not used. Therefore, the results were synthesised using narrative summary accompanied by visualisation of study findings. We constructed custom plots designed to illustrate each study's findings to provide a visual summary of the strength of the evidence for each outcome. We plotted the reported effect size if the paper reported this; if studies did not report effect size but reported sufficient information to calculate it (eg, mean and SD), we calculated the standardised mean difference (SMD) using the $\mathrm{R}$ package metafor (online supplemental file 2). If $95 \%$ CIs or SEs were reported, these were converted to SD using the formula suggested in the Cochrane handbook 
(https://handbook-5-1.cochrane.org/chapter_7). When calculating the effect size within experimental studies that used within-subjects designs, we imputed correlations of 0.5 to account for repeated measurements; sensitivity analyses using correlations of 0.6 and 0.8 were also conducted to examine the extent to which the imputed correlation might affect the results (shown in online supplemental file 2). While we acknowledge that the interpretation of the magnitude of effect sizes is arbitrary and context-specific, for the purposes of plotting we classified effect sizes as negligible $(\mathrm{SMD}<0.20, \mathrm{OR}<1.50$ or correlation $(\mathrm{r})<0.10)$, small $(\mathrm{SMD}=0.20-0.49$, $\mathrm{OR}=1.50$ $2.49, \mathrm{r}=0.10-0.29)$, medium $(\mathrm{SMD}=0.50-0.79$, $\mathrm{OR}=2.50$ $4.29, \mathrm{r}=0.30-0.49$ ) or large ( $\mathrm{SMD} \geq 0.80, \mathrm{OR} \geq 4.30, \mathrm{r} \geq 0.50$ ) based on standard conventions. ${ }^{19}$

Within the plots, the included papers are ordered from most robust to least robust evidence, primarily on the basis of study design (eg, within-subjects prioritised over between-subjects) and sample size. Whether the finding of the study was statistically significant is denoted through a filled (black) symbol with the direction of the association denoted by a positive sign $(+)$, negative sign $(-)$, zero (0) or question mark (?) if the direction could not be ascertained; non-significant associations are unfilled. The strength of the effect size is denoted by number of boxes (one=negligible, two $=$ small, three $=$ medium, four $=$ large $)$ based on the reported or calculated effect size. Where the effect size was not reported and could not be calculated in a standardised way (eg, regression coefficient, graphical presentation of means), we plotted the findings with a triangle, filled (or not) to denote statistical significance. Significance was determined based on (1) the calculated or reported CIs not crossing 0 or (2) the study reported a $\mathrm{p}$ value $<0.05$ where effect size with CIs was not reported and could not be calculated.

Patient and public involvement

No patients involved.

\section{RESULTS}

\section{Search results}

The flow of studies through the review process is shown in figure 1. From the original 13036 unique records retrieved by the database searches, 31 were eligible for inclusion. An additional 5 papers were retrieved through reference lists and 5 papers were excluded (4 due to poor study quality), leaving 31 studies included in the review (see online supplemental file 3 for study details, including information on statistical modelling with covariates listed).

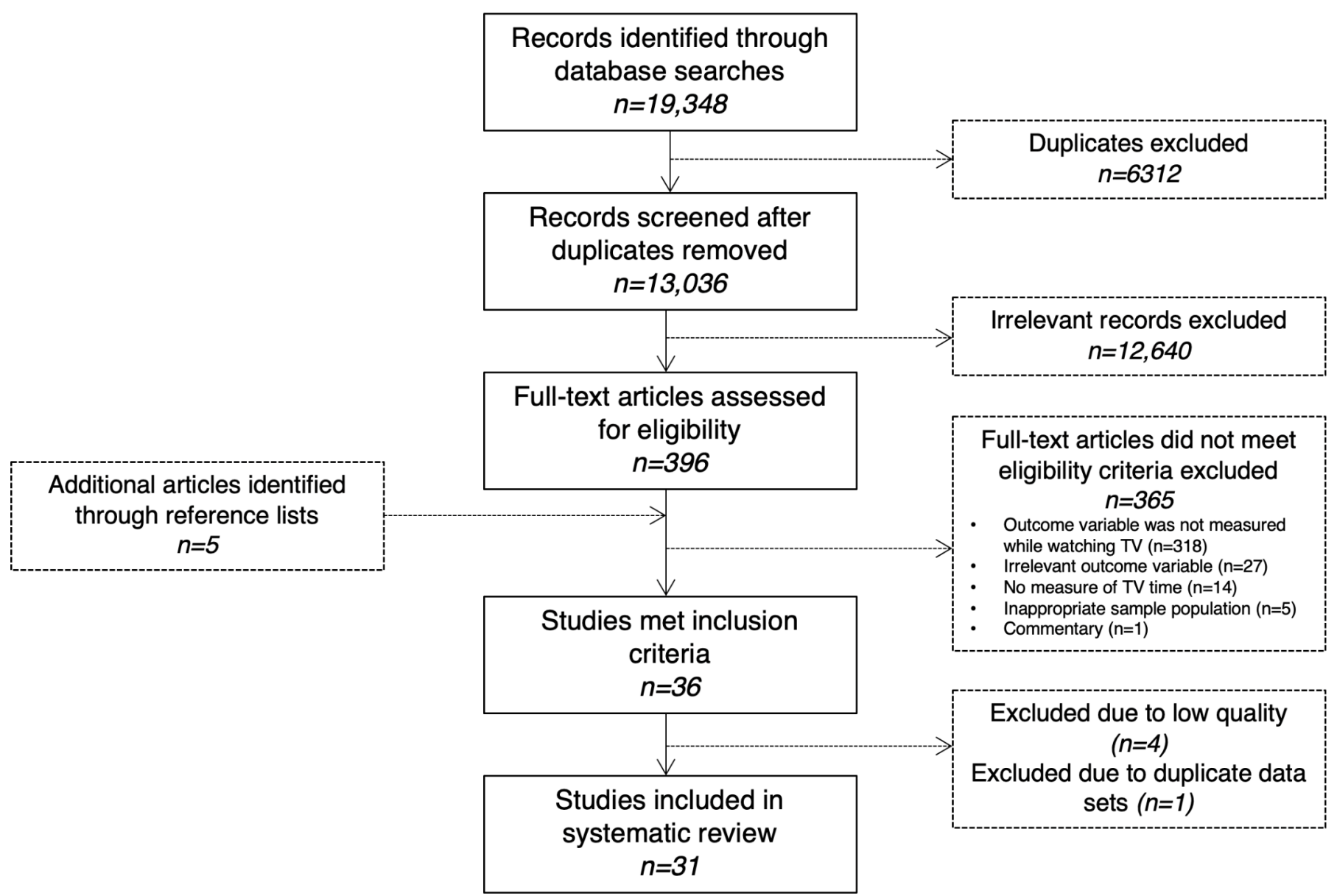

Figure 1 Flow of studies through the review process. 


\section{Characteristics of included studies}

Twenty-five studies were experimental, primarily focused on links between TV and food consumption $(n=19)$; the remainder focused on EE of sitting or movement while watching TV $(n=4)$ or the effects of TV on subsequent sleep $(n=2)$. Most experimental studies used a withinsubjects study design $(n=17)$ and were conducted in Europe $(n=11)$ or North America $(n=9)$, Australia $(n=3)$ and Japan $(n=2)$. Sample sizes ranged from 13 to $120 ; 10$ studies included only female participants while one study included only men.

Six studies were observational, including studies examining food consumption $(n=4)$ and affect $(n=2)$ while watching TV in free-living contexts. Five of these studies were based in the USA and one in New Zealand with sample sizes ranging from 40 to 538 .
Food and drink consumption while watching TV

Experimental studies

\section{TV versus doing nothing}

There is some evidence to suggest that more food is consumed while watching TV compared with while doing nothing else in a laboratory setting (figure 2 and online supplemental file 3). Nine experimental studies compared food consumption while watching TV compared with a control condition spent alone with no distraction. ${ }^{20-28}$ Seven studies found that participants had higher consumption in terms of energy intake $20-222426$ or mass ${ }^{26-28}$ during the TV condition compared with the control condition (generally small effect sizes), although this did not reach significance in most cases. In sensitivity analyses, effect sizes increased from small to medium in

\begin{tabular}{|c|c|c|c|c|}
\hline \multirow{2}{*}{ Study } & \multirow{2}{*}{ Study design (n) } & \multirow{2}{*}{ Outcome measure } & \multicolumn{2}{|c|}{ Association } \\
\hline & & & Overall & Women \\
\hline \multicolumn{5}{|l|}{ TV vs doing nothing } \\
\hline Hetherington 2006 & Within subjects $(n=37)$ & Meal intake (kJ) & + & \\
\hline Martin 2009 & Within subjects $(n=48)$ & Meal intake (kcal) & $\triangle$ & \\
\hline Rosenthal 2017 & Within subjects $(n=20)$ & Meal intake (kcal, g) & + & \\
\hline Moray 2007 & Within subjects $(n=20)$ & Meal intake (ounces) & $\triangle$ & \\
\hline Braude 2014 & Within subjects $(n=62)$ & Snack intake (kJ) & & \\
\hline Bellisle 2004 & Within subjects $(n=48)$ & Meal intake (kJ) & & + \\
\hline Bellisle 2009 & Within subjects $(n=40)$ & Meal intake $(\mathrm{kJ}, \mathrm{g})$ & & ? \\
\hline Ogden 2013 & Between subjects $(n=81)$ & Snack intake $(g)$ & & + \\
\hline Mittal 2010 & Between subjects $(n=32)$ & Snack intake (kJ) & & +++ \\
\hline \multicolumn{5}{|c|}{ TV vs other condition } \\
\hline Hetherington 2006 & Within subjects $(n=37)$ & With friends $(\mathrm{kJ})$ & & \\
\hline Hetherington 2006 & Within subjects $(n=37)$ & With strangers $(\mathrm{kJ})$ & $\triangle$ & \\
\hline Martin 2009 & Within subjects $(n=48)$ & While reading (kcal) & $\triangle$ & \\
\hline Bellisle 2004 & Within subjects $(n=48)$ & Listening to audio story $(\mathrm{kJ})$ & & - \\
\hline Bellisle 2009 & Within subjects $(n=40)$ & Listening to audio story $(\mathrm{kJ}, \mathrm{g})$ & & ? \\
\hline Bellisle 2009 & Within subjects $(n=40)$ & With strangers $(\mathrm{kJ}, \mathrm{g})$ & & $\AA$ \\
\hline Blass 2006 & Within subjects $(n=20)$ & Listening to music (kcal) & & \\
\hline \multirow[t]{2}{*}{ Lyons 2012} & \multirow{2}{*}{$\begin{array}{l}\text { Between subjects } \\
(n=120)\end{array}$} & With handheld video games (kcal) & - & \\
\hline & & $\begin{array}{l}\text { With motion-controlled video } \\
\text { games (kcal) }\end{array}$ & ++ & \\
\hline Ogden 2013 & Between subjects $(n=81)$ & While driving $(\mathrm{g})$ & & ++ \\
\hline Ogden 2013 & Between subjects $(n=81)$ & While talking to researcher (g) & & ++ \\
\hline
\end{tabular}

Figure 2 Summary plot of effect sizes for experimental effects of TV on food consumption compared with doing nothing else or doing something else. Strength of effect size is denoted by number of boxes (one=negligibleto four=large); triangles denote cases where effect size could not be calculated. Filled (black) symbols denote significant associations; non-significant associations are unfilled. 
two studies ${ }^{202}$ when a larger correlation coefficient was imputed (online supplemental file 2).

\section{$T V$ versus other activity}

There is little evidence to suggest that more food is consumed while watching TV compared with while doing other activities in a laboratory setting (figure 2 and online supplemental file 3). Seven studies compared food consumption while watching TV with consumption while doing other tasks, including listening to audio stories, ${ }^{20}{ }^{23}$ listening to classical music, ${ }^{29}$ reading, ${ }^{25}$ simulated driving, ${ }^{27}$ playing video games, ${ }^{30}$ eating with a researcher or strangers ${ }^{22} 27$ and eating with friends. ${ }^{22}$ Five of these studies reported no differences in the amount of food consumed between the TV condition and the other experimental condition they tested. ${ }^{2022} 232530$ The remaining two studies reported higher consumption while watching TV compared with while listening to classical music ${ }^{29}$ driving ${ }^{27}$ or while conversing with a researcher. ${ }^{27}$ Sensitivity analyses suggested larger imputed correlations did not materially change the findings (online supplemental file 2).

\section{Effect of TV on later consumption on the same day}

Three studies, all in laboratory settings, tested whether the consumption of a snack while watching TV (compared with while not watching TV) would result in higher food consumption at a meal or snack later on in the same day (consumed without TV) ${ }^{2431} 32$ (online supplemental file 3). Two of these studies found that when the earlier snack had been consumed while watching TV, significantly more was eaten in the subsequent TV-free meal/snack ${ }^{24}{ }^{31}$; the third did not find subsequent consumption was higher after the eating-with-TV exposure. ${ }^{32}$

\section{Role of TV content}

There is little evidence to suggest that the content of TV being watched influences food consumption in experimental settings (online supplemental file 3 ). Four studies examined food consumption when exposed to food advertisements compared with either neutral (non-food) advertisements ${ }^{33-35}$ or no advertisements, ${ }^{25} 35$ all reporting no main effect of commercial condition (although Anschutz et $a \hat{l}^{33}$ reported a significant interaction with gender such that women ate more when exposed to food commercials compared with neutral commercials but the opposite was true for men). Three studies evaluated the impact of TV content on food consumption ${ }^{24} 36$; two of these reported that participants ate more when watching boring or repeated showings of TV compared with engaging or novel TV, ${ }^{36}$ while the third reported no difference in consumption when participants watched funny, boring or sad TV shows. ${ }^{24}$ One study ${ }^{38}$ compared snack consumption following exposure to either a clip of a cooking show or a nature show, reporting no difference in overall consumption between the groups (although more chocolate balls were consumed following exposure to the cooking show than the nature show).
Observational studies

Four observational studies examined dietary patterns while watching TV in free-living settings among voluntary/convenience samples of adults in New Zealand, ${ }^{39}$ African-American women in Chicago ${ }^{40}$ and young adults in the $\mathrm{USA}^{4142}$ (figure 3 and online supplemental file 3 ).

The most detailed evidence comes from the study by Gemming et $a \vec{l}^{39}$ in New Zealand, which linked 24-hour dietary recalls to wearable camera recordings on three separate measurement days, allowing for an in-depth assessment of the contextual details (eg, location, environment, social context, presence of screens) surrounding each eating episode noted in the recall. In their sample, $17 \%$ of eating episodes (22\% of meals and $12 \%$ of snacks) took place while watching TV. Snacks consumed while watching TV were higher in energy (by $514 \mathrm{~kJ}$ (123 kcal)) than snacks consumed when no TV was viewed. There was no difference in meal energy intake or duration of meals or snacks while watching TV compared with when no screen was viewed.

The remaining three studies examined the contexts of self-reported eating and drinking using ecological momentary assessment ${ }^{40}$ and food diary entries annotated with contextual information. ${ }^{41}{ }^{42}$ These studies found that $30 \%$ and $26 \%{ }^{41}$ of snacking and eating occasions, respectively, took place while watching TV. Among young adults in the USA, Stroebele and de Castro ${ }^{42}$ reported that an average of 1.03 meals per day took place with the TV on, but meal size did not differ with or without the TV on. Compared with food and drink consumed while 'not doing anything else', a larger proportion of snacks ${ }^{40}$ and sugar-sweetened beverages ${ }^{41}$ and smaller proportions of water, fruit, vegetables and cereals $/$ grains $^{41}$ were consumed while watching TV compared with while doing nothing else.

\section{Characteristics of sitting while watching TV}

Four experimental studies examined associations between watching TV and characteristics of sitting, specifically $\mathrm{EE}^{43-45}$ and level of movement. ${ }^{46}$ Three experimental studies compared the EE of watching TV with the EE of other sedentary behaviours. ${ }^{4-45}$ The most robust evidence indicated that the EE of sitting while watching TV was lower than the EEs of typing, playing a handheld video game (both small effect sizes), and playing a screen-based video game while sitting (large effect size; figure 4$).{ }^{45}$ The other two studies found no difference between the EE of watching TV and the EE of typing at a desk, ${ }^{44}$ reading at a desk $^{44}$ or working on a laptop computer ${ }^{43}$ in their samples (figure 4 and online supplemental file 3), although their relatively small sample sizes and lack of a priori power calculations may mean their non-significant findings were due to underpowered samples.

A laboratory-based study compared the level of movement captured using hip-worn, triaxial accelerometry while watching TV (seated on a chair without armrests) compared with other sedentary behaviours among adults. ${ }^{46}$ Total movement (which we calculated as vector 


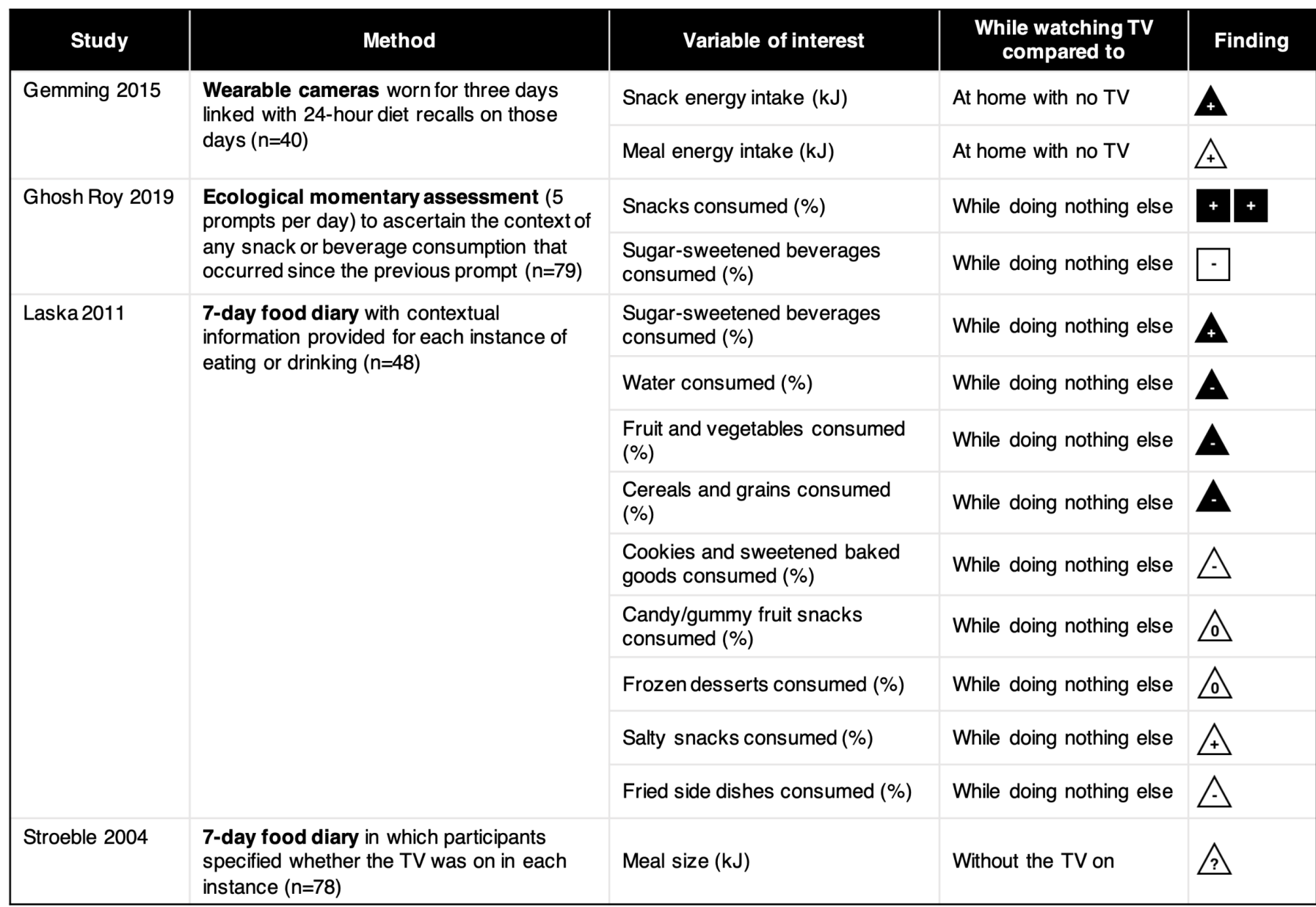

Figure 3 Summary plot of eating patterns while watching TV in free-living contexts. Strength of effect size is denoted by number of boxes (one=negligible to four=large); triangles denote cases where effect size could not be calculated. Filled (black) symbols denote significant associations; non-significant associations are unfilled.

\begin{tabular}{|c|c|c|c|}
\hline Study & Study design (n) & Outcome measure & Finding \\
\hline \multicolumn{4}{|c|}{ Experimental studies } \\
\hline \multicolumn{4}{|c|}{ Energy expenditure (EE) } \\
\hline \multirow[t]{3}{*}{ Mansoubi 2015} & \multirow[t]{3}{*}{ Within subjects $(n=51)$} & EE TV vs typing & \\
\hline & & EE TV vs handheld game (PSP) & \\
\hline & & EE TV vs seated video game (Wii) & \\
\hline \multirow[t]{2}{*}{ Newton 2013} & \multirow[t]{2}{*}{ Within subjects $(n=25)$} & EE TV vs typing & \\
\hline & & EE TV vs reading & - \\
\hline Creasy 2016 & Between subjects $(n=36)$ & EE TV vs computer & -9 \\
\hline \multicolumn{4}{|l|}{ Levelof movement } \\
\hline \multirow[t]{7}{*}{ van der Berg 2019} & \multirow[t]{7}{*}{ Within subjects $(n=18)$} & Acceleration TV vs reading & \\
\hline & & Acceleration TV vs writing & \\
\hline & & Acceleration TV vs typing & \\
\hline & & Acceleration TV vs playing cards & 0 \\
\hline & & $\begin{array}{l}\text { Acceleration TV vs preparing food while } \\
\text { seated }\end{array}$ & + \\
\hline & & Acceleration TV vs 'natural'sitting & \\
\hline & & Acceleration TV vs sitting motionless & 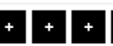 \\
\hline
\end{tabular}

Figure 4 Summary plot of effect sizes for characteristics of sitting while watching TV. Strength of effect size is denoted by number of boxes (one=negligible to four=large); triangles denote cases where effect size could not be calculated. Filled (black) symbols denote significant associations; non-significant associations are unfilled. 


\begin{tabular}{|c|c|c|c|}
\hline Study & Study design (n) & Outcome measure & Finding \\
\hline \multirow[t]{24}{*}{ Kuykendall 2020} & \multirow[t]{24}{*}{ Cross-sectional $(n=538)$} & Positive activated affect & \\
\hline & & TV vs physically active leisure & \\
\hline & & TV vs social leisure & \\
\hline & & TV vs cognitively stimulating leisure & \\
\hline & & TV vs creative leisure & \\
\hline & & TV vs cultural activities & \\
\hline & & Positive deactivated affect & \\
\hline & & TV vs physically active leisure & $\angle$ \\
\hline & & TV vs social leisure & $\triangle$ \\
\hline & & TV vs cognitively stimulating leisure & \\
\hline & & TV vs creative leisure & \\
\hline & & TV vs cultural activities & $\Delta$ \\
\hline & & Negative activated affect & \\
\hline & & TV vs physically active leisure & \\
\hline & & TV vs social leisure & \\
\hline & & TV vs cognitively stimulating leisure & \\
\hline & & TV vs creative leisure & $\triangle$ \\
\hline & & TV vs cultural activities & $\triangle$ \\
\hline & & Negative deactivated affect & \\
\hline & & TV vs physically active leisure & \\
\hline & & TV vs social leisure & \\
\hline & & TV vs cognitively stimulating leisure & \\
\hline & & TV vs creative leisure & \\
\hline & & TV vs cultural activities & \\
\hline \multirow[t]{8}{*}{ Goodwin 2005} & \multirow[t]{8}{*}{ Cross-sectional $(n=69)$} & Positive affect & \\
\hline & & TV vs other leisure & \\
\hline & & TV vs productive activities & \\
\hline & & TV vs maintenance activities & - \\
\hline & & Negative affect & \\
\hline & & TV vs other leisure & 0 \\
\hline & & TV vs productive activities & - \\
\hline & & TV vs maintenance activities & 0 \\
\hline
\end{tabular}

Figure 5 Summary plot of effect sizes for affect while watching TV. Strength of effect size is denoted by number of boxes (one=negligible to four=large); triangles denote cases where effect size could not be calculated. Filled (black) symbols denote significant associations; non-significant associations are unfilled.

magnitude of acceleration) was higher while watching TV compared with while reading, writing, typing and sitting both 'naturally' (ie, with free movement) and motionless, but did not significantly differ from movement while playing cards or preparing food while seated (figure 4).

In sensitivity analyses using larger imputed correlation coefficients, the effect sizes slightly increased for the difference in the EE of TV compared with typing and for the difference in vector magnitude of acceleration for TV versus reading, preparing food and sitting naturally (online supplemental file 2).

\section{Affect during TV viewing}

In two studies, participants self-reported their affect while watching TV within their everyday lives (figure 5 and Online supplemental file 3). Using a day reconstruction approach for the previous day in which leisure activities and affect were reported, Kuykendall et $a l^{47}$ found that respondents generally experienced poorer affect while watching TV compared with while engaged in other leisure activities, in terms of lower positive activated and deactivated affect (energetic/alert/vigorous and peaceful/at ease/serene, respectively) and higher negative deactivated affect (bored/tired/dull). However, negative activated affect (anxious/jittery/nervous) was generally lower while watching TV compared with other leisure activities. In a separate sample using similar methods, levels of relaxation were higher while watching TV than during physical activity (but similar to other 
leisure activities), levels of happiness and satisfaction were lower when watching TV compared with other activities (except for physical activity, which was similar to TV), and feelings of sadness did not differ between TV and other leisure activities.

In a study using experience sampling methods over the course of a week, Goodwin et $a t^{48}$ found that mean positive affect scores were lower while watching TV compared with while engaging in other leisure activities (eg, hobbies) or while doing productive activities (eg, work or volunteering); negative affect score did not differ while watching TV compared with while doing any other activities. In sensitivity analysis, only the effect size of the difference in positive affect during TV versus productive activities increased (from small to medium) with larger imputed correlations (online supplemental file 2).

\section{Impact of TV viewing on sleep}

One small experimental study $(\mathrm{n}=13)^{49}$ and one small intervention study $(\mathrm{n}=16),{ }^{50}$ both in Japan, were included here (online supplemental file 3 ). Komada et a $t^{49}$ tested the effect of TV displays on melatonin and cortisol secretion at night in a laboratory setting. Melatonin and cortisol are hormones involved in the body's sleep-wake cycles, and the production of melatonin in the body promotes sleep and is known to be suppressed by bright light. ${ }^{51}$ Komada et $a l^{49}$ found that a TV display with higher blue light intensity was associated with a suppressive effect on melatonin levels but not on cortisol levels. Asaoka et a $\tilde{l}^{\tilde{0}}$ conducted an intervention in which university students and elderly adults limited their TV time to $30 \mathrm{~min}$ a day for 1 week, following a week-long 'control' in which participants went about normal activities. During the week of restricted TV time, the university students went to bed significantly earlier and slept significantly longer compared with the control week; the intervention had no effect on sleep duration among the elderly.

\section{DISCUSSION}

This critical systematic review aimed to improve our understanding of how TV might impact cardiometabolic health by evaluating and synthesising available fair-quality and high-quality evidence on the effects of watching TV on food consumption, characteristics of sitting, affect and subsequent sleep. Most of the associations found were weak or inconsistent. There was no strong evidence from laboratory or free-living settings to suggest that food consumption while watching TV is higher than food consumption in other contexts. There was also no clear evidence to suggest that sitting while watching TV (in laboratory contexts) might be a particularly 'sedentary' behaviour. The association between TV and affect was complex. Positive affect and certain aspects of negative affect (eg, anxiousness or nervousness) tended to be lower while watching TV compared with other leisure activities, while other aspects of negative affect (eg, sadness) did not differ; feelings of tiredness or boredom were higher while watching TV compared with other leisure activities. There was a very small amount of evidence to suggest TV may impact sleep by suppressing melatonin and by impacting bedtime, at least in younger people.

The evidence on the impact of watching TV on food consumption is weak. In laboratory contexts in which fixed (and often large) amounts of food were placed in front of participants, participants tended to consume more while watching TV compared with while doing nothing else but more often than not this difference was not statistically significant, and there was very little evidence that consumption was higher while watching TV than during other potentially distracting activities such as listening to music. There is a very small amount of evidence that consumption of food while watching TV (compared with doing nothing) may be associated with greater subsequent intake than consumption while not watching TV. Evidence from free-living contexts, in which TV viewing conditions and food availability are quite different, suggested that energy intake while watching TV versus not did not significantly differ for meals but differed by a small amount for each snacking episode. ${ }^{39} 42$ Observational studies found $17 \%-26 \%$ of eating events and $12 \%-30 \%$ of snacking events occurred while watching $\mathrm{TV}^{39-41}$; however, no evidence was available to describe what proportion of TV-watching was accompanied by eating to determine whether TV 'triggers' food consumption. It is worth highlighting that the studies cited most often as evidence to suggest links between TV and snacking or higher food intake are not based on measurements of food consumption while watching TV; rather, this evidence shows that those with higher TV time have higher total energy consumption, higher snack intake or less-healthy diets than those with lower TV time with the causality of this association entirely unclear. ${ }^{52-56}$ Further research in free-living contexts is needed to improve our understanding of the possible co-occurrence of TV watching and food consumption to test the hypothesis that watching TV leads to greater energy intake or greater intake of foods associated with cardiometabolic risk. The use of devices such as wearable cameras (eg Gemming et $\left.a l^{p 9}\right)$ may prove particularly useful for this to assess the contexts of eating episodes (with and without TV), the contexts of TV viewing episodes (with and without eating) and the co-occurrence of the two. TV viewing may also affect diet in other ways not examined here.

There was little evidence to suggest that TV might be a particularly 'sedentary' behaviour. Compared with other seated activities, one of three experimental studies found that EE was lower while watching TV and another experimental study showed incidental movement was higher while watching TV. The ecological validity of these findings is unclear as the settings for TV watching in these studies (eg, on chairs without armrests, for short and fixed amounts of time) do not reflect TV-watching conditions in free-living contexts. We did not find any studies that examined whether watching TV may induce prolonged uninterrupted bouts of sitting, which have been shown to 
interfere with glucose and lipid metabolism. ${ }^{57}{ }^{58}$ We also did not find any studies that examined the characteristics of sitting while watching TV in free-living contexts. There is evidence that those with higher self-reported TV time have higher free-living accelerometer-measured prolonged sedentary time ${ }^{59}$ and fewer breaks in sedentary time,${ }^{5960}$ but these studies do not provide evidence that this prolonged sedentary time or lack of breaks is directly linked with time spent watching TV. Further research in free-living contexts should make use of mixed methodologies, for example, by combining accelerometry with wearable cameras, using electromyographic shorts and diaries, or applying direct observation methods (see Aunger and Wagnild ${ }^{61}$; Troiano et $a l^{62}$ for review) to improve our understanding of characteristics of sitting specifically during TV viewing.

There is little evidence to support the hypothesis that TV may impact cardiometabolic health via impacting affect. The two studies that examined affect while watching TV (both in free-living contexts) found that positive affect and feelings of happiness tended to be lower while watching TV than during other leisure activities, while the relationship between negative affect and TV depended on what aspect of negative affect was measured; overall negative affect and feelings of sadness were not higher or lower while watching TV, boredom and tiredness was higher, and anxiousness and nervousness were lower while watching TV compared with during other leisure activities. ${ }^{47} 48$ These findings suggest that TV may be a form of leisure that is 'numbing' in that it may ease negative feelings but not necessarily increase positive feelings. The role of TV in everyday lives as a method of stress management and relaxation and as a way to escape negative or depressed feelings has been previously described ${ }^{63-66} \mathrm{In}$ light of this, it is possible that measured mood or affect while watching TV may represent 'emotional spillover' from activities preceding TV time. ${ }^{47}$ From a measurement perspective, it would be useful to assess how affect might change over the course of TV viewing instances to better understand how TV might alter emotional states throughout the course of viewing.

Mental health status may be an important confounder of the association between TV and cardiometabolic health. Depression, for example, has been prospectively associated with both high TV time ${ }^{67}$ and poor cardiometabolic health outcomes. ${ }^{68}$ There is mixed evidence suggesting prospective associations between TV time and depression or depressive symptoms. ${ }^{69-72}$ Further research is needed to disentangle the relationships between TV, mood/affect and mental health, and cardiometabolic health outcomes.

There is a very small body of evidence to suggest that TV time may impact sleep, which may in turn impact cardiometabolic health. One small study included in this review found that blue light from a TV display suppressed melatonin, ${ }^{49}$ which may lead to a disruption in circadian rhythms, and another small study found that a reduction in TV time led to an earlier bedtime in young people. ${ }^{50}$
Thus, TV time may be linked to sleep disruption and later bedtimes, but much more evidence is needed to demonstrate this effect. The hypothesis that watching TV reduces sleep quantity or quality should be tested in people during their everyday lives, and might involve using wearable cameras to assess TV time and accelerometry to assess sleep quality and quantity.

This review did not identify strong evidence for any mechanism through which TV time has been posited to adversely impact cardiometabolic health. It is possible, however, that these factors may interact or have a multiplicative effect. For example, the combination of low EE of sitting while watching TV (based on laboratory evidence) with the slightly higher energy intake from snacks while watching TV could potentially produce a larger effect than either of these aspects on their own.

Importantly, even if such associations are observed in everyday lives, causality requires careful consideration as they may be the result of confounding, whereby, for example, chronic stress may prompt consumption of calorically dense foods ${ }^{73}$ and may also prompt TV-watching as a way to relax, perhaps concurrently. More generally, while the association between socioeconomic position (SEP) and TV time is likely to vary globally across cultural and economic contexts, low SEP is consistently linked to high TV time in 'western' countries such as the UK, ${ }^{74}$ the USA, ${ }^{75}$ Australia $^{76}$ and Canada. ${ }^{77}$ Within these contexts, low SEP itself is associated with some of the outcomes considered here, as well as with poor cardiometabolic health outcomes ${ }^{78-81}$ and may thus confound the relationship between TV viewing, diet, sitting characteristics, affect and sleep, and health outcomes. More empirical evidence, particularly using ethnographic or mixed-methods approaches, is needed to understand the place of TV in everyday lives and its potential role in the development of cardiometabolic disease, with particular attention to the question of whether watching TV is causally implicated in changing health-related practices. Experimental studies are also useful in helping disentangle causality.

The findings of this review must be interpreted in light of the limitations in the evidence base. The vast majority of included studies reported statistically significant results but often with very small effect sizes, suggesting possible publication bias. The associations seen in this review should therefore be interpreted with caution as statistically significant findings may be over-represented in the literature base. The majority of included studies examining food consumption and characteristics of sitting were laboratory-based, thus the ecological validity of such findings is unclear. Methods that capture these kinds of data in free-living contexts, such as use of wearable cameras or electromyographic shorts, may be useful for providing insights into the ways in which TV occurs in real-life settings. These methods will also be relevant for examining the contexts and possible health-related consequences of screen-related practices more broadly beyond just TV time. Key strengths of this review include its systematic approach and that it is the first to comprehensively examine and evaluate evidence of the assertions 
commonly made in the literature explaining why TV is particularly detrimental to cardiometabolic health.

\section{CONCLUSIONS}

There is currently no strong evidence to suggest that TV impacts cardiometabolic health via effects on food consumption, prolonged/inactive sitting, affect or sleep. Further research exploring the putative mechanism(s) by which TV viewing might impact cardiometabolic health is required. We suggest that studies make use of innovative and/or mixed methods, such as wearable cameras, participant observation or diaries, to improve our understanding of how TV fits within everyday lives and how it may impact cardiometabolic health outcomes, or whether relationships between TV time and cardiometabolic health reflect confounding.

\section{Twitter Janelle M Wagnild @jwagnild}

Acknowledgements The authors wish to thank the Anthropology of Health Research Group at Durham University for helpful feedback, and Professor Adetayo Kasim for providing statistical advice.

Contributors JMW led the study. Both authors (JMW and TMP) contributed to the design, database searches, data collection and analysis. JMW constructed the plots. Both authors (JMW and TMP) contributed to and approved the final manuscript.

Funding JW was supported by Durham University.

Competing interests None declared.

Patient consent for publication Not required.

Provenance and peer review Not commissioned; externally peer reviewed.

Data availability statement All data relevant to the study are included in the article or uploaded as supplementary information. All data generated or analysed during this study are included in this published article and its supplementary information files.

Supplemental material This content has been supplied by the author(s). It has not been vetted by BMJ Publishing Group Limited (BMJ) and may not have been peer-reviewed. Any opinions or recommendations discussed are solely those of the author(s) and are not endorsed by BMJ. BMJ disclaims all liability and responsibility arising from any reliance placed on the content. Where the content includes any translated material, BMJ does not warrant the accuracy and reliability of the translations (including but not limited to local regulations, clinical guidelines, terminology, drug names and drug dosages), and is not responsible for any error and/or omissions arising from translation and adaptation or otherwise.

Open access This is an open access article distributed in accordance with the Creative Commons Attribution Non Commercial (CC BY-NC 4.0) license, which permits others to distribute, remix, adapt, build upon this work non-commercially, and license their derivative works on different terms, provided the original work is properly cited, appropriate credit is given, any changes made indicated, and the use is non-commercial. See: http://creativecommons.org/licenses/by-nc/4.0/.

ORCID iDs

Janelle M Wagnild http://orcid.org/0000-0003-3933-6380

Tessa M Pollard http://orcid.org/0000-0002-0544-0158

\section{REFERENCES}

1 Patterson R, McNamara E, Tainio M, et al. Sedentary behaviour and risk of all-cause, cardiovascular and cancer mortality, and incident type 2 diabetes: a systematic review and dose response metaanalysis. Eur J Epidemiol 2018;33:811-29.

2 Grøntved A, Hu FB. Television viewing and risk of type 2 diabetes, cardiovascular disease, and all-cause mortality: a meta-analysis. JAMA 2011;305:2448-55.

3 Pinto Pereira SM, Power C. Sedentary behaviours in mid-adulthood and subsequent body mass index. PLoS One 2013;8:e65791.
4 Ekelund U, Tarp J, Steene-Johannessen J, et al. Dose-response associations between accelerometry measured physical activity and sedentary time and all cause mortality: systematic review and harmonised meta-analysis. BMJ 2019;366:14570.

5 Ekelund U, Steene-Johannessen J, Brown WJ, et al. Does physical activity attenuate, or even eliminate, the detrimental association of sitting time with mortality? A harmonised metaanalysis of data from more than 1 million men and women. Lancet 2016;388:1302-10.

6 Pinto Pereira SM, Ki M, Power C. Sedentary behaviour and biomarkers for cardiovascular disease and diabetes in mid-life: the role of television-viewing and sitting at work. PLoS One 2012; 7:e31132

7 Hu FB, Li TY, Colditz GA, et al. Television watching and other sedentary behaviors in relation to risk of obesity and type 2 diabetes mellitus in women. JAMA 2003;289:1785-91.

8 Wennman $\mathrm{H}$, Vasankari T, Borodulin K. Where to sit? type of sitting matters for the Framingham cardiovascular risk score. AIMS Public Health 2016;3:577-91.

9 Dempsey PC, Hadgraft NT, Winkler EAH, et al. Associations of context-specific sitting time with markers of cardiometabolic risk in Australian adults. Int J Behav Nutr Phys Act 2018;15:114.

10 Chastin SFM, Dontje ML, Skelton DA, et al. Systematic comparative validation of self-report measures of sedentary time against an objective measure of postural sitting (activPAL). Int J Behav Nutr Phys Act 2018;15:21.

11 Wijndaele K, DE Bourdeaudhuij I, Godino JG, et al. Reliability and validity of a domain-specific last 7-d sedentary time questionnaire. Med Sci Sports Exerc 2014;46:1248-60.

12 Clark BK, Sugiyama T, Healy GN, et al. Validity and reliability of measures of television viewing time and other non-occupational sedentary behaviour of adults: a review. Obes Rev 2009;10:7-16.

13 Maher CA, Mire E, Harrington DM, et al. The independent and combined associations of physical activity and sedentary behavior with obesity in adults: NHANES 2003-06. Obesity 2013;21:E730-7.

14 Stamatakis $\mathrm{E}$, Hamer M, Tilling $\mathrm{K}$, et al. Sedentary time in relation to cardio-metabolic risk factors: differential associations for selfreport vs accelerometry in working age adults. Int $\mathrm{J}$ Epidemiol 2012;41:1328-37.

15 Wagnild JM, Hinshaw K, Pollard TM. Associations of sedentary time and self-reported television time during pregnancy with incident gestational diabetes and plasma glucose levels in women at risk of gestational diabetes in the UK. BMC Public Health 2019;19:575.

16 Whitaker KM, Buman MP, Odegaard AO, et al. Sedentary behaviors and cardiometabolic risk: an isotemporal substitution analysis. $\mathrm{Am} \mathrm{J}$ Epidemiol 2018;187:181-9.

17 Stamatakis E, Ekelund U, Ding D, et al. Is the time right for quantitative public health guidelines on sitting? A narrative review of sedentary behaviour research paradigms and findings. $\mathrm{Br} J$ Sports Med 2019;53:377-82.

18 Stamatakis E, Davis M, Stathi A, et al. Associations between multiple indicators of objectively-measured and self-reported sedentary behaviour and cardiometabolic risk in older adults. Prev Med 2012;54:82-7.

19 Cohen J. Statistical power analysis for the behavioral sciences. Hillsdale: Lawrence Erlbaum Associates, 1988.

20 Bellisle F, Dalix AM, Slama G. Non food-related environmental stimul induce increased meal intake in healthy women: comparison of television viewing versus listening to a recorded story in laboratory settings. Appetite 2004;43:175-80.

21 Braude L, Stevenson RJ. Watching television while eating increases energy intake. examining the mechanisms in female participants. Appetite 2014;76:9-16.

22 Hetherington MM, Anderson AS, Norton GNM, et al. Situational effects on meal intake: a comparison of eating alone and eating with others. Physiol Behav 2006;88:498-505.

23 Bellisle F, Dalix A-M, Airinei G, et al. Influence of dietary restraint and environmental factors on meal size in normal-weight women. A laboratory study. Appetite 2009;53:309-13.

24 Mittal D, Stevenson RJ, Oaten MJ, et al. Snacking while watching TV impairs food recall and promotes food intake on a later TV free test meal. Appl Cogn Psychol 2011;25:871-7.

25 Martin CK, Coulon SM, Markward N, et al. Association between energy intake and viewing television, distractibility, and memory for advertisements. Am J Clin Nutr 2009;89:37-44.

26 Rosenthal R, Raynor $\mathrm{H}$. The effect of television watching and portion size on intake during a meal. Appetite 2017;117:191-6.

27 Ogden J, Coop N, Cousins C, et al. Distraction, the desire to eat and food intake. towards an expanded model of mindless eating. Appetite 2013;62:119-26. 
28 Moray J, Fu A, Brill K, et al. Viewing television while eating impairs the ability to accurately estimate total amount of food consumed. Bariatr Nurs Surg Patient Care 2007;2:71-6.

29 Blass EM, Anderson DR, Kirkorian HL, et al. On the road to obesity: television viewing increases intake of high-density foods. Physiol Behav 2006;88:597-604.

30 Lyons EJ, Tate DF, Ward DS, et al. Energy intake and expenditure during sedentary screen time and motion-controlled video gaming Am J Clin Nutr 2012:96:234-9.

31 Higgs S, Woodward M. Television watching during lunch increases afternoon snack intake of young women. Appetite 2009;52:39-43.

32 Ogden J, Oikonomou E, Alemany G. Distraction, restrained eating and disinhibition: An experimental study of food intake and the impact of 'eating on the go'. J Health Psychol 2017;22:39-50.

33 Anschutz DJ, Engels RCME, van der Zwaluw CS, et al. Sex differences in young adults' snack food intake after food commercial exposure. Appetite 2011;56:255-60.

34 Boyland EJ, Burgon $\mathrm{RH}$, Hardman CA. Reactivity to television food commercials in overweight and lean adults: physiological, cognitive and behavioural responses. Physiol Behav 2017;177:182-8.

35 Wonderlich-Tierney AL, Wenzel KR, Vander Wal JS, et al. FoodRelated advertisements and food intake among adult men and women. Appetite 2013;71:57-62.

36 Chapman CD, Nilsson VC, Thune Hanna $\AA$, et al. Watching TV and food intake: the role of content. PLoS One 2014;9:e100602.

37 Mathur U, Stevenson RJ. Television and eating: repetition enhances food intake. Front Psychol 2015;6:1657.

38 Bodenlos JS, Wormuth BM. Watching a food-related television show and caloric intake. A laboratory study. Appetite 2013;61:8-12.

39 Gemming L, Doherty A, Utter J, et al. The use of a wearable camera to capture and categorise the environmental and social context of self-identified eating episodes. Appetite 2015;92:118-25.

40 Ghosh Roy P, Jones KK, Martyn-Nemeth P, et al. Contextual correlates of energy-dense snack food and sweetened beverage intake across the day in African American women: an application of ecological momentary assessment. Appetite 2019;132:73-81.

41 Laska MN, Graham D, Moe SG, et al. Situational characteristics of young adults' eating occasions: a real-time data collection using personal digital assistants. Public Health Nutr 2011;14:472-9.

42 Stroebele N, de Castro JM. Television viewing is associated with an increase in meal frequency in humans. Appetite 2004;42:111-3.

43 Creasy SA, Rogers RJ, Byard TD, et al. Energy expenditure during acute periods of sitting, standing, and walking. J Phys Act Health 2016;13:573-8.

44 Newton RL, Han H, Zderic T, et al. The energy expenditure of sedentary behavior: a whole room calorimeter study. PLoS One 2013;8:e63171.

45 Mansoubi M, Pearson N, Clemes SA, et al. Energy expenditure during common sitting and standing tasks: examining the $1.5 \mathrm{Met}$ definition of sedentary behaviour. BMC Public Health 2015;15:516.

46 van der Berg JD, Stehouwer CDA, Bosma H, et al. Dynamic sitting: measurement and associations with metabolic health. J Sports Sci 2019:37:1746-54.

47 Kuykendall L, Lei X, Zhu Z, et al. Leisure choices and employee well-being: comparing need fulfillment and well-being during TV and other leisure activities. Appl Psychol Health Well Being 2020;12:532-58

48 Goodwin PE, Intrieri RC, Papini DR. Older adults' affect while watching television. Act Adapt Aging 2005;29:55-72.

49 Komada Y, Aoki K, Gohshi S, et al. Effects of television luminance and wavelength at habitual bedtime on melatonin and cortiso secretion in humans. Sleep Biol Rhythms 2015;13:316-22.

50 Asaoka S, Fukuda K, Tsutsui Y, et al. Does television viewing cause delayed and/or irregular sleep?wake patterns? Sleep Biol Rhythms 2007;5:23-7

51 Claustrat B, Brun J, Chazot G. The basic physiology and pathophysiology of melatonin. Sleep Med Rev 2005;9:11-24.

52 Bowman SA. Television-viewing characteristics of adults: correlations to eating practices and overweight and health status. Prev Chronic Dis 2006;3:A38.

53 Scully M, Dixon H, Wakefield M. Association between commercial television exposure and fast-food consumption among adults. Public Health Nutr 2009;12:105-10.

54 Thomson M, Spence JC, Raine K, et al. The association of television viewing with snacking behavior and body weight of young adults. Am $J$ Health Promot 2008;22:329-35.

55 Charreire H, Kesse-Guyot E, Bertrais S, et al. Associations between dietary patterns, physical activity (leisure-time and occupational) and television viewing in middle-aged French adults. Br J Nutr 2011;105:902-10.
56 Robinson SM, Crozier SR, Borland SE, et al. Impact of educational attainment on the quality of young women's diets. Eur J Clin Nutr 2004;58:1174-80.

57 Dunstan DW, Kingwell BA, Larsen R, et al. Breaking up prolonged sitting reduces postprandial glucose and insulin responses. Diabetes Care 2012;35:976-83.

58 Benatti FB, Ried-Larsen M. The effects of breaking up prolonged sitting time: a review of experimental studies. Med Sci Sports Exerc 2015;47:2053-61.

59 Shibata A, Oka K, Ishii K, et al. Objectively-assessed patterns and reported domains of sedentary behavior among Japanese older adults. J Epidemiol 2019;29:334-9.

60 Wagnild JM, Pollard TM. Associations between television time and activPAL-Measured duration and pattern of sedentary time among pregnant women at risk of gestational diabetes in the UK. J Phys Act Health 2020;17:471-4.

61 Aunger J, Wagnild J. Objective and subjective measurement of sedentary behavior in human adults: a toolkit. Am J Hum Biol 2020;n/a(n/a:e23546.

62 Troiano RP, Pettee Gabriel KK, Welk GJ, et al. Reported physical activity and sedentary behavior: why do you ask? J Phys Act Health 2012;9 Suppl 1:S68-75.

63 Teychenne M, Ball K, Salmon J. Perceived influences on and strategies to reduce sedentary behavior in disadvantaged women experiencing depressive symptoms: a qualitative study. Ment Health Phys Act 2011:4:95-102.

64 Tefertiller A, Sheehan K. Tv in the streaming age: motivations, behaviors, and satisfaction of post-network television. J Broadcast Electron Media 2019:63:595-616.

65 Barwise P, Bellman S, Beal V. Why do people watch so much television and video? implications for the future of viewing and advertising. J Advert Res 2020;60:121-34.

66 Warren TY, Wilcox S, St George SM, et al. African American women's perceived influences on and strategies to reduce sedentary behavior. Qual Health Res 2018;28:1112-22.

67 Teychenne M, Abbott G, Ball K, et al. Prospective associations between sedentary behaviour and risk of depression in socioeconomically disadvantaged women. Prev Med 2014;65:82-6.

68 Scott KM, Depression SKM. Depression, anxiety and incident cardiometabolic diseases. Curr Opin Psychiatry 2014;27:289-93.

69 Andrade-Gómez E, Martínez-Gómez D, Rodríguez-Artalejo F, et al. Sedentary behaviors, physical activity, and changes in depression and psychological distress symptoms in older adults. Depress Anxiety 2018;35:884-97.

70 Sui X, Brown WJ, Lavie CJ, et al. Associations between television watching and CAR riding behaviors and development of depressive symptoms: a prospective study. Mayo Clin Proc 2015;90:184-93.

71 Teychenne M, Abbott G, Lamb KE, et al. Is the link between movement and mental health a two-way street? prospective associations between physical activity, sedentary behaviour and depressive symptoms among women living in socioeconomically disadvantaged neighbourhoods. Prev Med 2017;102:72-8.

72 Lucas M, Mekary R, Pan A et al. Relation between clinical depression risk and physical activity and time spent watching television in older women: a 10-year prospective follow-up study. Am J Epidemiol 2011;174:1017-27.

73 Adam TC, Epel ES, Stress EES. Stress, eating and the reward system. Physiol Behav 2007;91:449-58.

74 Stamatakis E, Coombs N, Rowlands A, et al. Objectivelyassessed and self-reported sedentary time in relation to multiple socioeconomic status indicators among adults in England: a crosssectional study. BMJ Open 2014;4:e006034.

75 Yang L, Cao C, Kantor ED, et al. Trends in sedentary behavior among the US population, 2001-2016. JAMA 2019;321:1587-97.

76 Clark BK, Sugiyama T, Healy GN, et al. Socio-demographic correlates of prolonged television viewing time in Australian men and women: the AusDiab study. J Phys Act Health 2010;7:595-601.

77 Herman KM, Saunders TJ. Sedentary behaviours among adults across Canada. Can J Public Health 2016;107:E438-46.

78 Agardh E, Allebeck P, Hallqvist J, et al. Type 2 diabetes incidence and socio-economic position: a systematic review and metaanalysis. Int J Epidemiol 2011;40:804-18.

79 Addo J, Ayerbe L, Mohan KM, et al. Socioeconomic status and stroke. Stroke 2012;43:1186-91.

80 Manrique-Garcia E, Sidorchuk A, Hallqvist J, et al. Socioeconomic position and incidence of acute myocardial infarction: a metaanalysis. J Epidemiol Community Health 2011;65:301-9.

81 Stringhini S, Carmeli C, Jokela M, et al. Socioeconomic status and the $25 \times 25$ risk factors as determinants of premature mortality: a multicohort study and meta-analysis of 1.7 million men and women. Lancet 2017;389:1229-37. 